REVISTA DE DERECHO UNED, NÚM. 21, 2017

\title{
TRATAMIENTO JURÍDICO DE UN BINOMIO COHESIONADO EN LA NUEVA LEY ORGÁNICA DE PROTECCIÓN DE SEGURIDAD CIUDADANA; IDENTIFICACIÓN Y DOCUMENTOSCOPIA
}

\author{
LEGAL TREATMENT OF A COHESIVE BINOMIAL IN THE NEW \\ ORGANIC LAW OF CITIZEN SECURITY PROTECTION: \\ IDENTIFICATION AND DOCUMENT EXAMINATION
}

\author{
VALENTín Guillén PÉREZ \\ Doctor en Abogacía y Práctica Jurídica de la UCAM. Cabo de la Policía \\ Local de San Pedro del Pinatar \\ JAVIER PRIETo GonZÁLEZ
}

Licenciado en Derecho en la UCM. Inspector de Policía Nacional

Resumen: La nueva regulación de la Ley Orgánica 4/2015, de 30 de marzo, de Protección de Seguridad Ciudadana, constituye, para la ciencia de la documentoscopia, una antesala jurídico-legal que facilitará a los funcionarios policiales examinar las medidas de seguridad de un documento identificativo, con el propósito de evitar, o más bien detectar, un fraude en el tráfico jurídico fiduciario. Por todo lo cual, el presente artículo, va a centrar su atención en la cohesión de la disciplina de la documentoscopia con los aspectos más controvertidos que contiene esta nueva Ley Orgánica concernientes a la práctica de la identificación, al traslado a efectos de identificación, y a la exhibición de un documento. En este sentido, el propósito esencial de este estudio no es otro sino para que las Fuerzas y Cuerpos de Seguridad una vez requieran la identificación a un ciudadano, consigan, de forma eficaz e inequívoca, conocer la verdadera identidad del sometido a dicha práctica, guardando el justo equilibrio conque garantizar la protección de sus derechos fundamentales. 
Palabras clave: documentoscopia, identificación, traslado a efectos de identificación, exhibición documental.

Abstract: The new regulation of Organic Law 4/2015, of 30 March, on the Protection of Citizen Security, constitutes, for the science of the documents, a prior legal step that will facilitate the police officers to examine the security measures of an identification document, with the purpose of avoiding, or rather detecting, a fraud in the fiduciary legal traffic. Therefore, the present paper will focus on the cohesion of the discipline of document examination with the most controversial aspects contained in this new Organic Law concerning the practice of identification, the transfer for identification purposes, and the documentary exhibition. In this sense, the essential purpose of this study is none other than for the Security Forces and Bodies once they require the identification of a citizen, to obtain, in an effective and unequivocal way, to know the true identity of the subject to that practice, keeping the right balance to ensure the protection of their fundamental rights.

Keywords: document examination, identification, transfer for identification purposes, documentary exhibition.

Recepción original: 20/07/2017

Aceptación original: 27/10/2017

Sumario: I. Introducción. II. Existencia de un marco legal: la LOPSC como instrumento regulador de las identificaciones. II.A Requisitos para una práctica legítima de identificación. II.B El traslado a efectos de identificación. III. Correlación entre la documentoscopia y la identificación: exhibición del documento. IV. Introducción a la documentoscopia desde el prisma policial. V. Conclusión. VI. Bibliografía.

\section{INTRODUCCIÓN}

El campo de actuación de la documentoscopia es entendido mayoritariamente, por la doctrina científica, como «la rama de la criminalística que tiene por objeto el estudio de escritos y documentos de trascendencia legal, a fin de determinar su autenticidad o falsedad, así como, en su caso, la identidad de los autores» ${ }^{1}$. Además, esta dis-

${ }^{1}$ En términos de Nieto Alonso, J., Apuntes de Criminalística, Ed. Tecnos, Madrid, 1998, pág. 147. La doctrina realiza infinidad de definiciones, como destaca DeL PICHIA, J., Tratado de Documentoscopia. La falsedad documental, Ed. La Rocca, Buenos Aires, 1993, pág. 36, en cuyo caso hace una conceptualización en un sentido muy similar, entendiéndola como «la disciplina relativa a la aplicación práctica y metódica de los conocimientos científicos, teniendo como objetivo verificar la autenticidad o determinar la autoría de los documentos». Destacamos, además a los autores: RAÑE AguiLÁ, L., "La Criminalística y sus diferentes disciplinas forenses para la investiga- 
ciplina científica, comprende una naturaleza flexible, dúctil y cambiante, lo que resulta de interés social, en aras de erradicar la criminalidad en su conjunto y las nuevas modalidades delictivas.

Todo lo cual hace que, naturalmente, las Fuerzas y Cuerpos de Seguridad (FCS en adelante) deban actualizarse constantemente para adaptarse a las demandas que emitan las Administraciones de justicia como ejercicio de la función jurisdiccional, y más aún en nuestros días, con el perfeccionamiento y la aparición de nuevas técnicas de falsificación ${ }^{2}$ que hacen que el delincuente vaya siempre un paso por delante con respecto al investigador.

De este modo, opinamos que se podrá afrontar con más rigor la tarea ardua y compleja por parte de las FCS para tratar de comprender los nuevos modus operandi de las organizaciones criminales en nuestra sociedad ${ }^{3}, \mathrm{y}$, como consecuencia de ello, poder minimizar el efecto del delito ${ }^{4}$.

ción criminal», Diario La Ley, núm. 8332, Sección práctica forense, 2014, pág. 2. DE Antón y Barberá y De Luis y Turégano, Policía científica, Vol. 2, 4. ${ }^{\circ}$ Edición, Ed. Tirant lo Blanch, Valencia, 2004, pág. 139, Tobajas Santamaría, G., Domínguez Peralta, R. M., y GonzÁLez Yubero, A., "Diploma de actualización profesional/Perito judicial en documentoscopia», 1. ${ }^{a}$ Edición, Asesoramiento y defensa de los derechos del policía, Ed. Uned, 2013, pág. 6, CABAllero Chaparro, J., «Documentoscopia», Repositorio Institucional de la Universidad de Málaga, 2015, pág. 1, recurso electrónico: (http:// www.europeana.eu/portal/es/record/2022701/oai_riuma_uma_es_10630_9428.html), Mendoza BremaunTz, E., "La investigación científica del delito», Revista Criminogénesis, núm. 1, México, 2007 pág. 457, Colina ARENAS, J. D., «Apuntes acerca de la documentoscopia como disciplina auxiliar de la criminalística», Revista Facultad de Ciencias Forenses y de la Salud, núm. 8, Noviembre 2012, pág. 22, Miguel Salas, I., «El análisis de los documentos y la perspectiva criminológica», en EzEIBA RAMOs, J. (Dir.), Universidad del País Vasco. Euskal Herriko Unibertzitatea, 2015, pág. 21, disponible en https://addi.ehu.es/bitstream/handle/10810/19007/Miguel\%20Salas\%2c\%20 Iraia\%201.pdf?sequence=1\&isAllowed=y, y GRILLO M. A., "La falsificación de documentos, la importancia del perito documentológico privado», Revista Jurídica: Gaceta Judicial, República Dominicana, 1998, pág. 1, entre otros.

${ }^{2}$ En este sentido señala OMBELLI, D. y KNOPJES F., "Documentos: manual para desarrolladores», Ed. Organización Internacional para Migraciones, Ginebra, 2011, pág.56.

${ }^{3}$ Martínez Atienza, G., Seguridad pública y privada, Ed. Vlex, Barcelona, 2016, pág. 213, asevera que, la delincuencia organizada obtiene a través de los avances tecnológicos una influencia cada vez más exuberante sobre nuestra sociedad. En un mismo sentido afirma MAGAZ Álvarez, R., «Respuestas políticos-criminales a la delincuencia internacional: narcotráfico y terrorismo", en Collado MedinA, J., La investigación criminal y sus consecuencias jurídicas, Ed. Dykinson, 2010, Madrid, pág. 126, al aducir que las tecnologías emergentes favorecen la delincuencia internacional. Agudo Fernández, E., Jaén Vallejo, M., y Perrino Pérez, A. L., Terrorismo en el siglo XXI, Ed. Dykinson, Madrid, 2016, pág. 21, esgrime la importancia de las nuevas tecnologías para los diferentes grupos de terrorismo islámicos existentes.

${ }^{4}$ En similar sentido se expresa ColONIA, J. D., «Apuntes acerca...», op. cit., 2012, pág. 22. 
Teniendo en cuenta que los métodos científicos que reúne el campo de la documentoscopia es tan amplio, nos vamos a centrar fundamentalmente en desarrollar una adecuada praxis "técnico-jurídico», para, con ello, detectar, a pie de calle, una falsedad documental ${ }^{5}$ identificativa, en aras de conseguir unos medios de identificación fiables; es decir, aseverarnos que el documento identificativo-administrativo exhibido a requerimiento de un agente de la autoridad en el ejercicio de sus funciones, es auténtico y corresponde con la realidad.

En otro orden de cosas, pero manteniendo una cohesión propia con la documentoscopia, y, por ello, es deseable reseñar, que la identificación plantea una variada problemática que exige para poder abordarla con eficacia, delimitar, con claridad, cuáles son los elementos jurídicos que la configuran para realizarla con garantías y seguridad jurídicas, dado que, la identificación de una persona confiere la confrontación de dos principios constitucionalmente reconocidos; nos referimos al binomio en tensión aparentemente e irresoluble entre seguridad y libertad ${ }^{6}$.

En este sentido, vamos a desarrollar los aspectos jurídicos de relevancia policial con el fin de realizar una correcta identificación, y, con ello, conseguir que los derechos fundamentales del sometido a una identificación sean respetados al mismo tiempo que los funcionarios policiales no se vean envueltos en una detención ilegal. A este respecto, y desde una prisma constitucional, estudiaremos, en el presente trabajo, los aspectos de interés del artículo 16 de la Ley Orgánica 4/2015, de 30 de marzo, de Protección de la Seguridad Ciudadana, para después abordar los aspectos prácticos para una efectiva detección de una falsedad en documentos de viaje ${ }^{7}$.

\footnotetext{
${ }^{5}$ Nos vamos a referir a las dos conductas típicas que en general se suele distinguir entre las falsedades; la material; entendida como una alteración, creación total o parcial de un documento, así como la ideológica; concerniente a lo que no es verídico a pesar de que el documento se considere legítimo.

${ }^{6} \mathrm{El}$ conflicto, entre libertad y seguridad, es patente en cuanto que las antedichas leyes facultan, a los miembros de las FCS, para realizar cuantas actuaciones sean precisas para llevar a cabo, con eficacia, las indagaciones, las pesquisas o las investigaciones que les encomienda la legislación dentro del marco de sus funciones de prevención y represión del delito, y que suponen una molestia para el ciudadano, pues el derecho a la libertad de este último se verá afectado, como consecuencia de la práctica de los referidos cacheos, identificaciones y privaciones transitorias de la libertad para deambular. La STS de 4 de febrero de 1994 (FJ 3..$^{\circ}$ ) señala, que el cacheo junto a las identificaciones y las retenciones, "han sido siempre seriamente controvertidos porque enfrentan el derecho fundamental a la libertad de un lado, y el derecho a la seguridad, a la investigación criminal y a la detención de los presuntos autores de hechos delictivos de otro".

${ }^{7}$ A la luz de esta disciplina, entendemos, que lejos de la subsecuente relevancia penal por la comisión de un delito de falsedad documental, nos encontramos que, a
} 


\section{EXISTENCIA DE UN MARCO LEGAL: LA LOPSC COMO INSTRUMENTO REGULADOR DE LAS IDENTIFICACIONES}

\section{II.A Requisitos para una práctica legítima de identificación}

A modo introductorio podemos definir la identificación como «la intervención consistente en obtener datos personales y suficientes de una persona para que pueda ser reconocida de forma unívoca e inequívoca ${ }^{8}$. En consecuencia, se puede establecer una clasificación de la misma, compuesta por la identificación administrativa; cuyo método no nos proporciona una absoluta veracidad en la individualización de la persona, y la identificación personal; cuya técnica es la que más nos interesa, dado que está estrechamente unida a la criminalística que forma parte en el ámbito de la documentoscopia ${ }^{9}$ (dactiloscopia y la identificación fisiognómica).

La nueva Ley Orgánica 4/2015, de 30 de marzo, de Protección de la Seguridad Ciudadana (LOPSC en adelante), regula en su artículo 16 , los requisitos básicos de actuación que deben velar los funcionarios policiales cuando requieran la identificación de una persona en el ejercicio de sus funciones.

Este precepto amplía los requisitos habilitantes según los fines contemplados por la $\mathrm{Ley}^{10}$, y además sustituye al ya derogado artícu-

la sombra de todo ello, existen sujetos cuya falsificación de los documentos de viaje -especialmente los pasaportes, al constituirse el principal medio de identificación-, son utilizados para ocultar su verdadera identidad, bien porque la justicia les persigue, o bien porque forman parte de una organización criminal o terrorista. En este sentido señala también GERCKE, M., «Enfoques jurídicos para tipificar el delito de hurto de identidad», Manual sobre los delitos relacionados con la identidad, Ed. Oficina de las Naciones Unidas contra la Droga y el Delito, Nueva York, 2013, págs. 15 y 16, así también como OMBeLli, D. y KNOPJES F., «Documentos: manual», op. cit., 2011, pág. 54, reconociendo que el uso de documentos identificativos fraudulentos no es un medio de por sí, sino más bien se trata de un medio para perpetrar delitos más graves.

${ }^{8}$ GARCía AlONSO, D., «Intervención policial en seguridad y protección ciudadana», Área de derecho penal, Universidad Pública de Extremadura, 2016, pág. 110.

${ }^{9}$ En el mismo sentido se expresa la Polizia Zientifikoaren Unitatea (Unidad de Policía Científica), «Operaciones fundamentales de criminalística», Gobierno Vasco, Departamento de Interior, País Vasco, 2000, pág. 4-6, esgrimiendo en este sentido que el objeto es utilizar técnicas científicas para determinar la identidad del delincuente de una forma inequívoca.

${ }^{10}$ En parecidos términos se pronuncia España Alcoba, F., «La nueva Ley de Seguridad Ciudadana y los derechos y libertades de la ciudadanía española», en RIVERA BeIRAS, I. (Dir.), Tesis doctoral, Universitat de Barcelona, 2015, pág. 15. Sin embargo DíAz ARIAS, A., "Documentación e identificación personal. Identificación de personas (Capítulo III), Jornadas de formación de formadores sobre la nueva Ley Orgánica 4/2015, de Protección de la Seguridad Ciudadana, Madrid, 2015, pág. 14, entiende que 
lo 20 de la antigua LOPSC de 1992 que fue objeto de un recurso de inconstitucionalidad, donde se resolvió positivamente por la distinguida y famosa sentencia 341/1993, de 18 de noviembre, del Pleno del Tribunal Constitucional. El Tribunal entendió que el traslado a dependencias policiales a efectos de identificación constituye una modalidad de privación de libertad ${ }^{11}$ que no puede considerarse como una detención a los efectos del art. 17 de la CE. Esta sentencia, junto a la demás jurisprudencia, ha servido que este nuevo artículo fuera adaptado a tal efecto.

A tenor de la exposición realizada, no es menos importante resaltar que las diligencias de identificación efectuada por las FCS, junto a las pruebas de alcoholemia, cacheos y registros, están considerados como una modalidad de privación de libertad ${ }^{12}$ que, indudablemente, «implica una medida coactiva que afecta, de alguna forma, tanto a la libertad, como a la libre circulación, en tanto que, como la identificación misma, comporta inevitable, la inmovilización durante el tiempo imprescindible para su práctica» ${ }^{13}$.

Resulta innegable que, la convergencia de valores jurídicos constitucionales que puedan ser vulnerados por las FCS cuando practiquen las identificaciones en vía pública, y consecuentemente puedan convertirse incluso -si no se actúa conforme al ordenamiento jurídicoen una detención ilegal por el inevitable desconocimiento técnico-jurídico de algunos funcionarios policiales sobre los requisitos que legitiman realizar un traslado a dependencias policiales a efectos de identificación, lo que genera una inseguridad jurídica y operativa en el marco de sus actuaciones.

En este sentido, consideramos acertada las tres modalidades de privación de libertad que arguye el Consejo de Estado en el año 2014, con el asunto del anteproyecto de la LOPSC ${ }^{14}$. En primer lugar, menciona las restricciones de libertad ${ }^{15}$, entendida como aquellas inmovi-

el nuevo artículo 16, contiene criterios más restrictivos que el que venía con la LOPSC de 1992.

${ }^{11}$ En el mismo sentido refiere DuARt Albiol, J. J., Inspecciones; registros e intervenciones corporales en el proceso penal, Ed. J. M. Bosch, Barcelona, 2014, pág. 239.

${ }^{12}$ El derecho a la libertad de toda persona, constituye un valor superior que conforma un derecho fundamental en nuestra Carta Magna, en cuyo caso no puede ser restringido a no ser que esté tipificado en una Ley Orgánica.

${ }^{13}$ Entre la innumerable jurisprudencia señalamos la STS 416/2012, de 7 de marzo $\left(\right.$ FJ $\left.1 .^{\circ}\right)$.

${ }^{14}$ Consejo de Estado; Dictamen número 557/2014, con fecha de aprobación el 26 de junio del 2014.

${ }^{15}$ Existe una parte de la jurisprudencia e incluso de la doctrina, que señala esta situación de privación de libertad como «restricciones de libertad». A modo de ejem- 
lizaciones deambulatorias que supongan una privación de libertad con una intensidad leve regulado en el artículo 16.1 de la LOPSC, que difiere con la figura de la detención. El segundo supuesto supone una medida más gravosa e intensa que la referida restricción, si bien ésta, se encuentra regulada en el artículo 16.2 de la referida Ley Orgánica. Y, por último, hace mención a la detención en sentido estricto, regulada en el artículo 17 de nuestra Carta Magna, y en la Ley de Enjuiciamiento Criminal.

En otro orden de cosas, y centrándonos en la lectura del artículo 16.1 de la LOPSC ${ }^{16}$, conviene llevar a colación y a su estudio, aquellas matizaciones interesantes en el campo de las actuaciones policiales con respecto a la diligencia de identificación.

La práctica de identificación en la vía pública siempre debe tener una justificación, evitando cualquier intervención caprichosa o arbitraria. Sobre este matiz estamos todos de acuerdo ${ }^{17}$, aunque, ahora bien, en opinión de quienes suscriben, existe un cambio ostensible de modo que no se podrá justificar genéricamente, como sucedía en la antigua LOPSC en aras de proteger la seguridad ciudadana ${ }^{18}$, sino que

plo destacamos a Banacloche Palao, J., La libertad personal y sus limitaciones, Ed. MacGraw-Hill, Madrid, 1996, pág. 56.

${ }^{16} \mathrm{El}$ artículo reza que «1. En el cumplimiento de sus funciones de indagación y prevención delictiva, así como para la sanción de infracciones penales y administrativas, los agentes de las Fuerzas y Cuerpos de Seguridad podrán requerir la identificación de las personas en los siguientes supuestos: a) Cuando existan indicios de que han podido participar en la comisión de una infracción. b) Cuando, en atención a las circunstancias concurrentes, se considere razonablemente necesario que acrediten su identidad para prevenir la comisión de un delito. En estos supuestos, los agentes podrán realizar las comprobaciones necesarias en la vía pública o en el lugar donde se hubiese hecho el requerimiento, incluida la identificación de las personas cuyo rostro no sea visible total o parcialmente por utilizar cualquier tipo de prenda u objeto que lo cubra, impidiendo o dificultando la identificación, cuando fuere preciso a los efectos indicados. En la práctica de la identificación se respetarán estrictamente los principios de proporcionalidad, igualdad de trato y no discriminación por razón de nacimiento, nacionalidad, origen racial o étnico, sexo, religión o creencias, edad, discapacidad, orientación o identidad sexual, opinión o cualquier otra condición o circunstancia personal o social».

${ }^{17}$ Existe una vasta jurisprudencia que esgrime dichos argumentos al respecto. Además la doctrina científica es unánime en señalar dicha circunstancia. A modo de ejemplo, señalamos a GUILLÉN ÁlvAREZ, I., «Estudio y análisis jurídico de la nueva Ley Orgánica 4/2015, de protección de la seguridad ciudadana», Diario la Ley, núm. 8633, 2015, pág. 7 o Alonso Pérez, F. (Coord.), Manual del policía, Ed La Ley, Madrid, 2004, pág. 3, y de una forma similar con el cacheo se pronuncia GuILlEn PÉREz, V., La práctica del cacheo en el sistema constitucional español, Ed. Iuris Universal, Murcia, 2016, págs. 55-62.

${ }^{18}$ Como así lo indica el Preámbulo de la actual LOPSC. 
será necesario que existan indicios de que han podido participar en la comisión de una infracción.

Resulta acreditativo realizar una reflexión al respecto, ya que dicho lo cual entendemos que la nueva redacción conduce a dos extremos de interés. El primero se circunscribe al término de concurrencias de «indicios» que aduce la nueva LOPSC para justificar una identificación. En la anterior regulación, se limitaba a establecer que las identificaciones estaban justificadas en el ejercicio de sus funciones de indagación o prevención. Naturalmente, la jurisprudencia ha ido marcando y modulando una doctrina férrea en la legitimación de las identificaciones, entendiendo, en este sentido, que bastan las meras sospechas y los indicios racionales ${ }^{19}$ para la preceptiva intervención propia de las FCS en concordancia con los artículos 282 de la LECR y el artículo 11.1 de la Ley Orgánica 2/1986 de 13 de marzo, de Fuerzas y Cuerpos de Seguridad.

A pesar de que parte de la doctrina ${ }^{20}$, pueda confundir los términos de «sospecha» y de «indicios», a nuestro modo de ver, existe una diferencia sustancial entre ambas locuciones. El indicio se puede definir como «aquella prueba de cargo, apta para destruir la presunción de inocencia ${ }^{21}$; es decir, se producirá una detención preventiva por haber pruebas o vestigios suficientes constatados por las FCS, de modo que conllevará a la investigación de un delito concreto (antigua imputación), e incluso el juez podrá tomar, en su caso, la consideración de restringir derechos fundamentales con motivo de la aportación fehaciente de indicios.

Por su parte, el término «sospecha» está definida como aquella circunstancia que implica la conjetura o suposición de que pudiera perpetrarse un ilícito penal ${ }^{22}$. No hay mejor forma de diferenciarlo

${ }^{19}$ A modo de ejemplo señalamos la STS 720/1993, de 17 de diciembre (FJ 1. ${ }^{\circ}$ ), para justificar la identificación de una persona y el registro de un vehículo, por el mero hecho de estar en una zona donde asiduamente se traficaba con droga.

${ }^{20}$ De modo palpable entendemos que la doctrina a la hora de discernir sobre el artículo 16.1 de la LOPSC, y concretamente cuando argumenta la justificación para la legítima práctica de la diligencia de identificación, embarullan ambos vocablos. En este sentido arguye GuILlÉN ÁlVAREZ, I., «Estudio y...», op. cit., 2015, pág. 7, que «el apartado a) podría tratarse de un cajón de sastre para la identificación de todas aquellas personas que parezcan sospechosas a ojos de los agentes, pues dicho apartado habla de indicios». También aludimos a nuestro autor DíAz ARIAS, A., "Documentación e...», op. cit., 2015, pág. 16, o también García Alonso, D., «Intervención policial...», op. cit., 2014, pág. 111.

${ }^{21}$ Fernández Martínez, J. M., (Coord.), Diccionario jurídico, Ed. Aranzadi, 2004, pág. 653.

${ }^{22}$ Guillén Pérez, V., «La práctica...», op. cit., 2016, pág. 56. 
que con el análisis que realiza la doctrina jurisprudencial. En este sentido, la STC 174/1985, de 17 de diciembre (FJ 6..$^{\circ}$ ), establece la distinción entre indicio y sospecha en los siguientes términos: "para trazar la distinción entre uno y otro supuesto, es decir, entre la existencia de una verdadera prueba indiciaria capaz de desvirtuar la presunción de inocencia, y la presencia de simples sospechas, conviene recordar los criterios usualmente aceptados sobre la cuestión. Una prueba indiciaria ha de partir de unos hechos (indicios) plenamente probados, pues no cabe evidentemente construir certezas sobre la base de simples probabilidades. De esos hechos que constituyen los indicios debe llegarse a través de un proceso mental razonado y acorde con las reglas del criterio humano a considerar probados los hechos constitutivos de delito».

En cualquier caso, y como se ha tenido ocasión de comprobar por los tribunales, existe una sentencia interesante, que ha marcado la forma de obtener los llamados «indicios racionales» en la participación de la comisión de un delito. Nos estamos refiriendo a la STC 2179/2002, de 23 de diciembre, en cuyos argumentos aclaraba los siguientes criterios:

- Criterios de ciencia: son aquellos que en su conjunto dimanan de una prueba pericial, como es el caso de las huellas lofoscópicas que permiten el descubrimiento de la participación de un sujeto en un hecho delictivo.

- Criterios de experiencia: relativos a la actividad diaria en la prevención de delitos que proporcionan importantes datos experienciales sobre la delincuencia.

- Criterios de lógica: concernientes a la deducción de las FCS en la existencia de un indicio determinante para creer que se ha cometido un hecho delictivo.

Estos criterios, han justificado, desde la promulgación de la LOPSC de 1992, las intervenciones en las diligencias de identificación, y consecuentemente evitar, así, las actuaciones intuitivas o aleatorias. Es reseñable que, incluso, se ha llegado a sentar como criterio para justificar las identificaciones, la propia experiencia de los funcionarios policiales que les permite valorar datos que pasarían desapercibidos a personas no expertas.

A modo de ejemplo, y partiendo de una praxis policial a tal efecto, estarían justificadas las identificaciones por las FCS, por el mero hecho de encontrar a personas en zonas de las llamadas calientes o crí- 
ticas $^{23}$, esquivar a la policía cambiando de dirección de forma repentina $^{24}$, o huir de un lugar sin causa aparente o justificada ${ }^{25}$, incluso cuando presentan un estado de nerviosismo impropio de la identificación $^{26}$, actitud extraña, o por la realización de movimientos inhabituales como agacharse o esconderse ${ }^{27}$.

Para mayor abundamiento, y desde un prisma jurisprudencial del criterio de la experiencia, encontramos sentencias que avalan intervenciones de los funcionarios policiales por razones profesionales, esgrimiendo que tienen o deben tener una especial capacidad para detectar la presencia de presuntos delincuentes ${ }^{28}$, o incluso ratifican la legalidad de algunas intervenciones policiales por la facultad y posesión de una formación especializada, que les permite apreciar y analizar con mayor agudeza datos o indicios ${ }^{29}$. Es decir, la doctrina jurisprudencial se conforma con la mera capacidad intuitiva del policía, o sospechas basadas en las reglas de la experiencia policial que les permiten apreciar la relevancia de datos y circunstancias que no son fáciles de expresar de un modo jurídico ${ }^{30}$.

Podemos apuntar de todo lo expuesto en referencia a los términos «indicios» y «sospechas», y de un modo sintético a tenor de la exposición realizada, que existe una diferenciación entre ambas locuciones en su terminología jurídica, pero no es menos cierto que la doctrina jurisprudencial ha ido modelando a lo largo del tiempo ambos términos, llegando a una notable laxitud que hacen que sean similares. En relación con lo expresado, se pronuncia Díaz Arias, razonando entre otras cosas, que ciertos conceptos jurídicos indeterminados se califican de vagos e imprecisos, como es el caso de la prevención, y de los «indicios» ${ }^{31}$.

En otro orden de cosas, resulta acreditativo realizar una reflexión sobre otro aspecto polémico del artículo 16 de la LOPSC. Nos referimos a la identificación de una persona en aras de denunciar una infracción administrativa. Dicho precepto es taxativo en aseverar que se

${ }^{23}$ ATS 153/1997, de 22 de enero.

${ }^{24}$ SAP de Madrid, 185/2015, de 27 de febrero.

${ }^{25}$ ATS 332/1998, de 28 de enero.

${ }^{26}$ STS 879/1993, de 15 de abril, SAP de Barcelona 161/2014, de 24 de febrero, STS $662 / 1994$, de 23 de febrero entre otras tantas.

${ }^{27}$ SAP de Barcelona 161/2014, de 24 de febrero.

${ }^{28}$ STS 792/2001, de 26 de abril, entre otras.

${ }^{29}$ STS 74/1996, de 2 de febrero.

${ }^{30}$ García Alonso, D., «Intervención policial...», op. cit., 2016, pág. 112.

${ }^{31}$ Díaz Arias, A., «Documentación e...», op. cit., 2015, pág. 18. 
podrá requerir la identificación «cuando existan indicios de que han podido participar en la comisión de una infracción».

Recordemos que es factible la identificación a fin de prevenir un acto delictivo; sin embargo, no caben identificaciones para evitar o prevenir por meras infracciones administrativas, al admitir la dificultad para calificar anticipadamente unos hechos que no han llegado a consumarse, ya que la Ley no lo prevé en este sentido ${ }^{32}$, e incluso la STC 341/1993, de 18 de noviembre, se ha pronunciado en este sentido en su fundamento jurídico quinto ${ }^{33}$.

En cualquier caso, sugerimos una solución operativa que pueda justificar una actuación policial referente a esta cuestión ${ }^{34}$. Desde la perspectiva de que algunas conductas tipificadas como infracciones administrativas se consideren agravadas en ciertas circunstancias, y consecuentemente puedan constituir en un ilícito penal. En este sentido, una identificación estaría encuadrada para prevenir en primera instancia una infracción penal o, secundariamente, sancionar una infracción administrativa.

A modo de ejemplo, señalamos que el consumo y la tenencia de drogas, ante la detección de sospechas, se podría intervenir en aras de prevenir un delito contra la seguridad pública; o también los grafiteros que deslucen los inmuebles podría incurrir en un delito leve o delito menos grave de daños; portar instrumentos peligrosos o armas podría estar encuadrado o calificado como delito, etc. Incluso la expresión que esgrime la LOPSC sobre «en atención a las circunstancias concurrentes en cada caso», nos lleva también a la conclusión de

${ }^{32}$ La identificación para prevenir una infracción administrativa, fue retirada del Proyecto presentado en Julio de 2014, debido a las objeciones planteadas por el informe al Anteproyecto de la LOPSC 4/2015 realizado por el Consejo General del Poder Judicial el 27 de marzo del 2014.

${ }^{33}$ Reza de la siguiente manera: «la orden o requerimiento para el desplazamiento con fines de identificación a dependencias policiales no podrá dirigirse a cualesquiera personas que no hayan logrado ser identificadas, supuesto que en que la gravosidad de la medida impondría un juicio de inconstitucionalidad por desproporcionalidad manifiesta, frente a esta previsión...la privación de libertad con fines de identificación (en base al art. 20.2 LOPSC 1/1992 que se corresponde con el actual art. 16 LOPSC) sólo podrá afectar a personas no identificadas de las que razonable y fundadamente pueda presumirse que se hallan en disposición actual de cometer un delito o a aquéllas que hayan incurrido ya en una infracción administrativa, estableciendo así la Ley un instrumento utilizable en los casos en que la necesidad de identificación surja de la exigencia de prevenir un delito o falta o de reconocer, para sancionarlo, a un infractor de la legalidad».

${ }^{34}$ En este sentido, se pronuncia Prieto González, J., Manuales operativos de intervención policial, Volumen 1, 2. ${ }^{\circ}$ edición, Ed. Netpol Seguridad S. L., Madrid, 2017, págs. 70 y 71 . 
que es factible la actuación policial en las diligencias de identificación en zonas críticas donde los toxicómanos frecuentemente consumen drogas; zonas de botellones donde se pueden producir delitos de lesiones, etc.

\section{II.B El traslado a efectos de identificación}

Como se ha tenido ocasión de entrever en apartados anteriores, analizaremos en este punto, y de una forma compendiada, los aspectos más ambiguos en cuanto a la interpretación se refiere del artículo 16.2 de la LOPSC 4/2015 35 : las llamadas «retenciones de libertad» realizadas por las FCS.

Este término jurídico es racionalmente necesario para incluirlo en una Ley Orgánica, como así lo reconoció el Ministro del Interior en la Sesión Plenaria ${ }^{36}$ del año 2015, durante el debate de la LOPSC 4/2015, y recogido en el diario de sesiones del Congreso de los Diputados, cuando señalaba que «...se regulan por primera vez en esta Ley cosas que hasta ahora no estaban reguladas (...) la retención, esa figura entre la detención y la libertad...».

Suponen una medida temporal más gravosa e intensa que las restricciones o inmovilizaciones deambulatorias, una vez que la actuación policial se circunscribe al traslado de una persona a las dependencias policiales más próximas a efectos de identificación. No debemos olvidar que el derecho fundamental a la liberad no es un derecho absoluto ${ }^{37}$, sino que puede ser limitado, ya que no es contrario a la Constitución Española, como refiere la sentencia del TC 341/1993, anteriormente comentada.

${ }^{35} \mathrm{El}$ artículo reza así: «cuando no fuera posible la identificación por cualquier medio, incluida la vía telemática o telefónica, o si la persona se negase a identificarse, los agentes, para impedir la comisión de un delito o al objeto de sancionar una infracción, podrán requerir a quienes no pudieran ser identificados a que les acompañen a las dependencias policiales más próximas en las que se disponga de los medios adecuados para la práctica de esta diligencia, a los solos efectos de su identificación y por el tiempo estrictamente necesario, que en ningún caso podrá superar las seis horas. La persona a la que se solicite que se identifique será informada de modo inmediato y comprensible de las razones de dicha solicitud, así como, en su caso, del requerimiento para que acompañe a los agentes a las dependencias policiales.»

${ }^{36}$ Sesión Plenaria núm. 269 de 26 de marzo de 2015 en la pág. 66, en la intervención del Ministro del Interior.

${ }^{37}$ STC $178 / 1985$, de 18 de noviembre. 
Sin embargo, respecto a la diligencia de identificación, la dificultad estriba cuando se procede al traslado del interesado a dependencias policiales sin causa justificada, o sin mediar los requisitos exigibles a tal efecto, en cuyo caso la acción de los agentes pudiera ser constitutivo de un delito de detención ilegal o, en su caso, un delito de coacciones.

Por consiguiente se debe cumplir una serie de requisitos para no vulnerar los derechos constitucionales del sometido ${ }^{38}$ :

- El tiempo empleado para la práctica de la identificación será el mínimo imprescindible, no pudiendo superar, en ningún caso, las 6 horas. Entendemos que el tiempo empezará a contar desde el preciso instante en que el individuo es conducido en el vehículo policial a dependencias.

- Las dependencias donde el sometido va a ser trasladado deberá cumplir lo siguiente: estar provisto de medios técnicos adecuados para una adecuada identificación y la máxima proximidad al lugar del requerimiento. No obstante lo anterior, estaría dentro del marco legal de actuación si se traslada al domicilio cercano del requerido, si alega tener allí la documentación ${ }^{39}$.

- Se deben agotar cualquier medio, incluida la vía telemática o telefónica que den fianzas bastantes al funcionario policial en el lugar del requerimiento.

- La finalidad del traslado debe tener al menos uno de los siguientes requisitos: impedir la comisión de un delito independientemente de su tipología, o sancionar una infracción.

Además de ello podemos añadir aquellas infracciones administrativas que permiten el traslado de una persona para sancionarlas, las cuales no están exentas de problemas de interpretación; de modo que la cuestión no es otra que dirimir la naturaleza de las referidas infrac-

${ }^{38}$ Además de todo lo expuesto, no es ocioso destacar que se le deberá informar, de modo inmediato y comprensible, de las razones del traslado. Respetar estrictamente los principios de proporcionalidad, igualdad de trato y no discriminación. Derecho a solicitar un habeas corpus por ser una modalidad de privación de libertad.

${ }^{39}$ Como esgrime la STS 1007/2002, 27 de mayo, al referir en el FJ 3. ${ }^{\circ}$ que «desde luego, no se atisba razón alguna que autorizan el traslado forzoso a comisaría al no poder identificarse el requerido a ello, pues, aparte de que tal identificación se pudo practicar por otro medio más sencillo y eficaz y menos traumático, ya que según indicó el requerido tenía la documentación en su cercano domicilio.» 
ciones para que el traslado de una persona, que no esté perfectamente documentada, se ajuste a la Ley.

Por consiguiente, la controversia no es otra que discernir si el precepto que nos ocupase refiere solamente a las infracciones que hace mención la LOPSC (artículos 35, 36 y 37), o, si, de lo contrario, abarcaría cualquier infracción emanada de las leyes, normas e incluso aquellas procedentes de un ordenamiento jurídico menor como son las ordenanzas municipales.

En primera instancia, la STC 341/1993, no aclara del todo esta cuestión. Hace una mención baladí al referirse «especialmente» a las reguladas en los artículos 23 y siguientes de la ya derogada LOPSC 1/1992; por lo que, en virtud de ello, entendemos que no excluye al resto de infracciones. Ahora bien, existe una vasta fundamentación jurídica como la doctrina ${ }^{40}$, la jurisprudencia ${ }^{41}$, el Dictamen del Consejo de Estado ${ }^{42}$ o la Secretaría General Técnica del Interior $^{43}$, entre otros, justificando que el traslado a efectos de sancionar una infracción debe poseer una naturaleza o incidencia en la seguridad ciudadana.

En cualquier caso, hasta el momento, no existe condena alguna a un miembro de las FCS por realizar un traslado con motivo de sancionar infracciones enmarcadas dentro de la seguridad ciudadana; aunque no es menos cierto que, atendiendo al principio de proporcio-

${ }^{40}$ Quereda TAPIA, A., "Análisis del régimen sancionador establecido en la Ley Orgánica 4/2015, de 30 de marzo, de Protección de la Seguridad Ciudadana», Revista del Gabinete Jurídico de Castilla la Mancha, 2015, pág. 16. CASAL HeRnándeZ, J. M., Derecho a la libertad personal y diligencias policiales de identificación, Ed. Centro de estudios políticos y constitucionales, Madrid, 1998, pág. 353 y Banacloche PaLAU, J., «La libertad...», op. cit., pág. 423.

${ }^{41}$ STC 341/1993, de 18 de noviembre, STS 669/1999, de 5 mayo. Interesantes argumentos encontramos en la STS 1007/2002, de 27 de mayo, esgrimiendo el alto tribunal sobre una infracción no incluida en materia de seguridad ciudadana: «no cabe considerar que hubiera puesto en peligro la seguridad ciudadana que hiciera necesaria su identificación para la protección de aquella seguridad».

${ }^{42}$ Dictamen del Consejo de Estado núm. 557/2014 de 26 de junio, sobre el anteproyecto de la LOPSC: «las previsiones del art. 16.2 deben lógicamente extenderse al supuesto de faltas administrativas de especial gravedad o generadoras de alarma social con la misma finalidad que la prevista en el caso de los delitos».

${ }^{43}$ Secretaria General Técnica del Ministerio del Interior. Consulta planteada el 29 de marzo de 2016, con número de registro 370: «respecto a la naturaleza de las infracciones administrativas y si quedarían incluidas aquellas distintas a las relacionadas con la protección de la seguridad ciudadana, se informa que conforme al art. 2 de la LOPSC 4/2015, la Ley tiene por objeto la regulación de actuaciones de diversa naturaleza orientadas a la tutela de la seguridad ciudadana, mediante la protección de personas y bienes y el mantenimiento de la tranquilidad de los ciudadanos, por lo que no quedarían incluidas aquellas infracciones de otra naturaleza». 
nalidad, sería ilegítimo trasladar a alguien a dependencias policiales a fin de sancionar una infracción no catalogada como de «seguridad ciudadana $»^{44}$.

Entendemos, por ende, que el legislador no ha estado acertado en la regulación de la LOPSC, al no incluir de una forma precisa y concreta, aquellas infracciones administrativas que motiven y amparen el traslado de una persona a dependencias policiales a efectos de identificación. Es por ello que consideramos que debieran haberse especificado, a tal efecto, todas aquellas infracciones administrativas que guarden cierta relevancia por su gravedad y alarma social. Opinamos que, de este modo, no se vulneraría el derecho a la libertad de las personas.

\section{CORRELACIÓN ENTRE LA DOCUMENTOSCOPIA Y LA IDENTIFICACIÓN: EXHIBICIÓN DEL DOCUMENTO}

Este apartado lo consideramos de crucial transcendencia, porque constituye un nexo de unión entre las identificaciones anteriormente reseñadas y la documentoscopia aplicada a las falsedades de documentos identificativos.

Este nexo está regulado por el capítulo II de la LOPSC ${ }^{45}$, cuyo contenido está confeccionado de una forma pormenorizada sobre la identificación de los españoles y los extranjeros en los términos recogidos en los artículos del 9 al 11, destacando, entre otros aspectos, la acreditación de la identidad ${ }^{46}$ de los ciudadanos españoles y extranjeros,

${ }^{44}$ No obstante, el concepto de seguridad ciudadana no está exento de interpretación normativa a lo largo del tiempo, desde la aprobación de la LOPSC de 1992. Centrándonos en el análisis que actualmente realiza la doctrina científica, podemos aducir que, el informe al anteproyecto de la LOPSC 4/2015 realizado por el Consejo General del Poder Judicial, de 27 de marzo de 2014, establece que la seguridad ciudadana es considerada como un componente de la seguridad pública. En definitiva, sigue argumentando el referido informe que, la seguridad pública puede definirse como aquella actividad dirigida a la protección de personas y bienes y al mantenimiento de la seguridad ciudadana definiendo esta última como el estado en el cual los ciudadanos gozan de una situación de tranquilidad y estabilidad que les permite ejercer de forma libre y responsable los derechos y las libertades reconocidos constitucionalmente. Por ello podemos concluir al respecto que entrarían dentro de la seguridad pública aquellas infracciones tanto de seguridad ciudadana como «de seguridad aérea, marítima, ferroviaria, vial o en los transportes» (art. 2.3 LOPSC 4/2015).

${ }^{45}$ Consideramos de igual modo como Bilbao UbiLlos, J. M., «La llamada ley mordaza: Ley Orgánica 4/2015 de Protección de la Seguridad Ciudadana», Teoría y Realidad Constitucional, núm. 36, Uned, 2015, pág. 54, esgrimiendo que este segundo capítulo se regula con mayor extensión con respecto al que regulaba la LOPSC 1/1992.

${ }^{46}$ Coincidimos con OTERo SoRIano, J. M., "Criminalística y policía científica», en Collado Medina, J. (Coord.), Teoría y Práctica de la Investigación Criminal, Ed. Insti-

(C) UNED. Revista de Derecho UNED, núm. 21, 2017 
obligaciones y derechos del titular del documento nacional de identidad y del pasaporte, así como las obligaciones y los derechos de sus titulares, el valor probatorio y los deberes de estos documentos.

Establece el artículo 8.1, de la LOPSC, que el Documento Nacional de Identidad es un «documento público y oficial y tendrá la protección que a éstos otorgan las leyes, así como suficiente valor por sí solo para la acreditación de la identidad y los datos personales de su titular»; además incorporará la fotografía, la firma de su titular, así como los datos personales que sean determinados reglamentariamente. De igual modo, esgrime el artículo 11 de la LOPSC que «el pasaporte español es un documento público, personal, individual e intransferible (...) acredita la identidad y nacionalidad de los ciudadanos españoles fuera de España, y dentro de territorio nacional».

No obstante, dicha Ley Orgánica, en referencia a la acreditación de la identidad de los ciudadanos extranjeros ${ }^{47}$, esgrime en su artículo 13, que estos ciudadanos deberán portar consigo la documentación preceptiva expedida por las autoridades competentes del país de origen o de procedencia, así como la que acredite su situación regular en España; es decir, la tarjeta de identidad de su país, su pasaporte, o bien la tarjeta de identificación de extranjeros (TIEX) emitida por las autoridades españolas.

Estos preceptos de la LOPSC nos lleva a la conclusión de que los documentos anteriormente mencionados, se configuran como los únicos que acreditarían fehacientemente a priori la identidad de los ciudadanos españoles y extranjeros a requerimiento de los agentes de la autoridad; pero en verdad no es así, puesto que la jurisprudencia ${ }^{48}$, la

tuto Universitario General Gutiérrez Mellado, Uned, Madrid, 2009, pág. 103, al definir la identidad como «la cualidad de algo de ser único, y es esta unicidad la que nos permite hablar de identificación e identificar el rastro dejado por una persona o por una herramienta».

${ }^{47} \mathrm{La}$ norma reguladora de los extranjeros en España se encuentra recogida en la Ley Orgánica 4/2000, de 11 de enero, sobre los derechos y libertades de los extranjeros en España y su integridad social, arguyendo en su artículo 1.1 que «se consideran extranjeros, a los efectos de la aplicación de la presente ley, a los que carezcan de la nacionalidad española».

${ }^{48}$ La Jurisprudencia ha admitido documentos distintos a los mencionados, como un carnet de biblioteca, carnet de universidad y permiso de conducción. De este último, lo estima la SAP de Madrid, de 31 de octubre de 2008, con recurso 340/2008, admitiendo que «el permiso de conducción es un documento con retrato y firma expedido por la autoridad pública que identifica a la persona del conductor y que nuestro ordenamiento lo admite literalmente en diversos supuestos, como los ya expuestos, como medio de identificación, habiendo reconocido la jurisprudencia y doctrina dicha función identificadora, aunque sea de forma subsidiaria». 
doctrina $^{49}$, las instrucciones ${ }^{50}$, e incluso la propia LOPSC ${ }^{51}$, demuestran que existen otros documentos totalmente válidos, y perfectamente útiles, para una plena identificación a todos los efectos. La Oficina de las Naciones Unidas contra la droga y el delito (UNODC), reconoce que el permiso de conducción es un instrumento útil para identificar a un sujeto. De hecho, reconoce que, los terroristas del 11 de septiembre, utilizaron permisos de conducción fraudulentos para identificar$\mathrm{se}^{52}$, y de este modo pasar desapercibidos.

De igual modo, sucede con los extranjeros, quienes podrán demostrar su identidad por cualquier otro medio si no la llevaran consigo ${ }^{53}$, siempre y cuando, el medio empleado le dé fianza bastante al funcionario policial actuante; es decir, en última instancia, quedaría a su criterio admitir o no como válido, el documento en cuestión.

De acuerdo con lo expuesto, se expresa Otamendi Zozaya ${ }^{54}$, en cuyos argumentos reseña que "será el policía quien deba valorar si la acreditación que ofrece el ciudadano extranjero, distinta de su pasaporte, para acreditar su identidad es suficiente». A modo de ejemplo, no sería válido un documento que no integre fotografía, porque cabe la posibilidad de que el documento presentado no se corresponda con el sometido a la identificación ${ }^{55}$.

En la antesala de la documentoscopia, en el ámbito de las actuaciones policiales en la LOPSC dirigidas a las diligencias de identificación, ésta se encuentra regulada, sin lugar a dudas, en los artículos 9 y 13 anteriormente referidos. Donde se hace referencia que tanto el documento nacional de identidad como al pasaporte son personales e intransferibles, como también se preceptuaba en la ya derogada LOPSC $1 / 1992$.

${ }^{49}$ Martínez Atienza, G., Seguridad pública y privada, Ed. Vlex, Barcelona, 2016, pág. 66, quien pone de ejemplo que un permiso de conducción no es un documento de identidad, como es obvio, pero los funcionarios policiales, a su criterio, podrían admitirlo como válido para identificarse.

${ }^{50}$ Instrucción 7/2015 de la Secretaría de Estado de Seguridad sobre la Ley Orgánica 4/2015 de Protección de la Seguridad Ciudadana, aduce que «cabe recordar que, en principio, puede considerarse adecuada la identificación conseguida por documentos oficiales distintos del DNI».

${ }^{51}$ El artículo 16.2 de la LOPSC, en referencia al traslado a efectos de identificación «cuando no fuera posible la identificación por cualquier medio».

52 Oficina de las Naciones Unidas contra la droga y el delito, «Manual sobre los delitos relacionados con la identidad», Naciones Unidas, Nueva York, 2013, pág. 16.

${ }^{53}$ Lo señala el propio artículo 13.1 de la LOPSC.

${ }^{54}$ Otamendi Zozaya, F., La nueva Ley Orgánica 4/2015, de Protección de la Seguridad Ciudadana: Una visión práctica, Ed. AMAL, Pamplona, 2015, pág. 43.

${ }^{55}$ En un sentido similar se pronuncia la SAP de Navarra, 41/2005, de 21 de marzo. 
Todo lo cual, naturalmente, antes de la entrada en vigor de la actual LOPSC, suscitaba una interpretación errónea, incluso reconocido por parte de la doctrina ${ }^{56}$, porque las locuciones «documento es intransferible» o «sin que pueda ser privado del mismo», cuestionaba el hecho de si el identificado se veía obligado a entregar el documento al agente de la autoridad que lo requiera a fin de examinarlo, o, por el contrario, era suficiente con enseñárselo, pero de ningún modo entregarlo físicamente. Ahora bien, deducimos, a este respecto, que el mero hecho de que un documento sea intransferible no quiere decir con ello que esté prohibido cogerlo física y temporalmente para la comprobación de un fin preventivo de seguridad. De igual modo, si acudimos al Real Decreto 1553/2005, de 23 de diciembre, por el que se regula la expedición del Documento Nacional de Identidad y sus certificados de firma electrónica, también generaba dudas, porque establece en su artículo 2.2, que todas las personas obligadas a obtener el DNI lo están también a exhibirlo cuando fueren requeridas por parte de los agentes de la autoridad.

Con la nueva regulación, y con el fin de salir al paso de ciertas interpretaciones torticeras, la actual LOPSC no deja opción a interpretación, ya que preceptúa de forma taxativa que cualquier ciudadano, ya sea español o extranjero, y que sea requerido por un agente de la autoridad para ser identificado, estará obligado no sólo exhibirlo, sino también a permitir la comprobación de las medidas de seguridad que impregna el mismo, puesto que los documentos cuentan con unas medidas de seguridad para garantizar que no pueda ser falsificado o alterado.

Por consiguiente, no tiene sentido que los organismos públicos hayan realizado unas inversiones pecuniarias con el fin de impregnar los documentos oficiales de medidas de seguridad, y por el contrario, las FCS estén limitadas a la hora de realizar la debida comprobación de los mismos. Así lo asevera nuestro autor García Alonso ${ }^{57}$ cuando explica que «será necesario que el agente lo manipule en sus propias manos con la finalidad de comprobar las medidas de seguridad del DNI como son: el soporte, la estructura de superficie, los fondos de seguridad, etc.». A modo ilustrativo, no podría comprobarse la medida de seguridad de la tinta ópticamente variable (tinta OVI), a no ser que el agente sujete el documento y lo incline a fin de verificar su cambio de color, así

${ }^{56}$ Puigserver Martínez, J. A., «La Ley Orgánica 4/2015, de 30 de marzo, de protección de la seguridad ciudadana», en MARTín DE VEGA, M. R. (Dir.), Seguridad y ciudadanía; Revista del Ministerio del Interior, núm. 14, Ed. Ministerio del Interior, 2015, pág. 54. Bilbao Ubillos, J. M., «La llamada...», op. cit., 2015, pág. 228. OtameNDI ZozAYA, F., «La nueva...», op. cit., 2015, pág. 39.

${ }^{57}$ García Alonso, D., «Intervención policial...», op. cit., 2016, pág. 125. 
como comprobar la existencia de la marca de agua, el láser en relieve, entre otras medidas, que verifiquen la autenticidad del mismo.

El artículo 8, de la LOPSC, recuerda que los documentos incorporan medidas de seguridad para que puedan ser examinados por los profesionales: «la tarjeta soporte del documento nacional de identidad incorporará las medidas de seguridad necesarias para la consecución de condiciones de calidad e inalterabilidad y máximas garantías para impedir su falsificación».

Es importante destacar, a tal efecto, que, en el supuesto de que el sometido a ser identificado a requerimiento del agente de la autoridad se negase a entregar el documento para que este último pudiere comprobar las medidas de seguridad, aquél incurriría en una infracción grave del artículo 36.6 de la LOPSC: «la desobediencia o la resistencia a la autoridad o a sus agentes en el ejercicio de sus funciones cuando no sean constitutivas de delito». Y en el supuesto de que aquél persistiera en una actitud terca, contumaz y obcecada en negarse a entregar el documento identificativo, y tras haber sido requerido en repetidas ocasiones para ello por las FCS, con las correspondientes advertencias legales, podría incluso incurrir en un delito de desobediencia grave penado en el artículo 556 de nuestro código penal.

Además, podemos señalar sobre la base de todo lo expuesto que, de igual manera que la LOPSC indica que los funcionarios policiales pueden comprobar las medidas de seguridad de un DNI o de un pasaporte a fin de verificar la autenticidad del mismo, no es menos cierto deducir de ello la legalidad de comprobar las medidas de seguridad de otro documento que incorpore también medidas de seguridad, y se encuentre incorporado al tráfico jurídico como son el permiso de conducir, los permisos de circulación, etcétera.

\section{INTRODUCCIÓN A LA DOCUMENTOSCOPIA DESDE EL PRISMA POLICIAL}

Como habíamos reseñado anteriormente las FCS deben de actualizarse constantemente en materia de la documentoscopia ${ }^{58}$, visto que

${ }^{58}$ No podemos olvidar que la documentoscopia es «una especialidad consagrada de la criminalística», véase la referencia de DíAZ SANTANA, O. F., «La prueba pericial de datación de documentos», Diario La Ley, núm. 8937, Sección Tribuna, 2017, pág. 1, o RaÑe Aguilá, L., destacando que la documentoscopia es una disciplina forense que se encuentra dentro de la criminalística ( La Criminalística y sus diferentes disciplinas forenses para la investigación criminal», Diario La Ley, núm. 8332, Sección práctica forense, 2014, pág. 2). 
en la actualidad con los avances tecnológicos, las falsificaciones son cada vez más elaboradas. Por tanto, el objetivo primordial de este colectivo no es otro que el deber de estar continuamente formados para la detección de creaciones fraudulentas que en ocasiones son muy precarias y no resisten un mínimo análisis «in situ», al tener los funcionarios policiales formados en la materia, unos resultados positivos incluso con menos conocimientos.

No obstante lo anterior, la mayoría de las veces no es así, y muy a menudo la detección del fraude se ve condicionada por la habilidad del falsario, dependiendo principalmente de elementos casuísticos y circunstanciales que el experto policial ha de saber descubrir y valorar en el trabajo de campo, con los indicios observados y consecuentemente proceder en el ámbito penal.

Primeramente, la definición de falsedad documental conduce a la necesidad de una aproximación del propio concepto de documento ${ }^{59}$. Si bien, el agente de la autoridad debe de tener un conocimiento jurídico de documento, para con ello conseguir una mejor praxis policial en la materia.

Además, desde una perspectiva dogmática, la definición de documento permite incluir cualquier soporte diferente al papel, incluso en cualquier grafía ${ }^{60}$. A modo de ejemplo, la falsificación, sustitución, alteración u omisión de una placa de matrícula de un vehículo a motor, los tribunales lo consideran un delito de falsedad documental, porque equipara el soporte de la placa de matrícula como un documento público, es decir, «la placa de matrícula tiene, por los datos que incorpora, relevancia jurídica ${ }^{61}$. Dicho lo cual, y centrándonos en el ordenamiento jurídico español, el actual Código Penal, concretamente en su artículo 26, lo define como: «todo soporte material que exprese o incorpore datos, hechos o narraciones con eficacia probatoria o cualquier otro tipo de relevancia jurídica».

Partiendo de dicha premisa, también debemos tener en cuenta que la reproducciones digitales (fotocopias) son considerados docu-

${ }^{59}$ Rojas Aguirre, L. E., "Falsedad documental como delito de engaño», Revista chilena de derechos, Vol. 41, núm. 2, 2014, pág. 3, aduce en este sentido, afirmando además que la definición conduce a una tautología, de la cual se deben de especificar los elementos que deben concurrir para estar en presencia de un documento.

${ }^{60}$ En parecidos términos, como señala el tratadista Albel Lluch, X., Derecho probatorio, Ed. Bosch Editor, Barcelona, 2012, pág. 787.

${ }^{61}$ Consulta 3/1997, de 19 de febrero, sobre la falsificación, sustitución, alteración u omisión de la placa de matrícula de un vehículo a motor. En otro orden de cosas, es unánime la consideración de la jurisprudencia los siguientes tipos de documentos: públicos, oficiales, mercantiles o privados, todos ellos destinados al tráfico jurídico. 
mentos $^{62}$, aunque durante algún tiempo la doctrina emanada de la jurisprudencia en relación a las mismas y su falsedad, no ha sido, ni mucho menos, uniforme. De modo que se les negó todo valor probatorio al no ofrecer garantías sobre la manipulación de su contenido y por consiguiente sobre su autenticidad.

En la actualidad, la más reciente jurisprudencia respecto al valor de las fotocopias en relación con el delito de falsedad documental, revela, que tienen la consideración de documentos, en cuanto que reflejan o plasman una idea, pero la reproducción fotográfica sólo transmite la imagen del documento, no su naturaleza jurídica, salvo una posterior autenticación (fotocopia compulsada), por lo que se consideran documentos privados ${ }^{63}$.

Ahora bien, en el caso de la simulación de un documento en todo o en parte, de manera que induzca a error sobre su autenticidad (art. 390.1.2. ${ }^{\circ}$ ), penalmente, lo más relevante se dirime en la naturaleza del documento que se pretende simular y no el medio utilizado para ello, y por tanto cuando se utiliza una fotocopia para simular la autenticidad de un documento, si dicho documento es público u oficial, se comete falsedad en documento público u oficial.

En otro orden de cosas, y en cuanto a la verificación de documentos, existen actualmente tres niveles significativos ${ }^{64}$ :

- Un primer nivel: concerniente al examen realizado sin utilizar ningún tipo de aparato que permita identificar un documento falso mediante una identificación visual y táctil, sin duda se puede equiparar como una inspección visual rápida.

- Un segundo nivel: mediante la utilización de unos pequeños medios no sofisticados, que posibilitan la detección de documentos falsificados, como por ejemplo lupas, cuentahílos, lámpara de wood o luz ultravioleta, lupa decodificadora ${ }^{65}$, dispositivos portátiles de inspección, mesa de luz blanca, cámara fotográfica, escáner portátil, lector de código de barras, retrowiever de $3 \mathrm{M}^{66}$, microscopio digital USB, etc.

${ }^{62}$ A modo de ejemplo, referenciamos una sentencia reciente como la STS 11/2015, de 29 de enero.

${ }^{63}$ Como así aduce la STS 386/2014, de 22 de mayo, FJ $1 .^{\circ}$

${ }^{64}$ Como destaca Ombelli, D. y Knopjes F., «Documentos: manual», op. cit., 2011, pág.290.

${ }^{65}$ Este instrumento, aporta una información no visible al ojo humano, de modo que es sólo perceptible bajo esta lupa.

${ }^{66}$ Este aparato, permite la verificación rápida si los documentos protegidos por los llamados laminados de $3 \mathrm{M}$, han sido o no manipulados. 
- El tercer nivel y último nivel refiere sobre el examen exhaustivo realizado por especialistas de la policía científica, cuyo estudio permite una evaluación profunda y detallada del documento. Además requiere la utilización de un equipamiento especial para realizar estas certificaciones; docubox, video spectro comparador o microscopios sofisticados entre otros.

Las medidas de seguridad que incorporan los documentos pueden ser controladas en el primer y segundo nivel principalmente. Si bien, de forma genérica están integradas en casi todos los documentos, porque son fabricados conforme a las medidas de seguridad recogidas tanto en la ISO 18013, como en el documento 9303 de la OACI (Organización Internacional de Aviación Civil). Sin embargo, existen otras directivas nacionales e incluso internacionales que regulan las medidas de seguridad de otros documentos concernientes a los permisos de conducción ${ }^{67}$ y los documentos de viaje.

Los elementos que pueden ser controlados se clasifican mediante el siguiente criterio:

1. Se integran en el soporte del documento durante el proceso de fabricación.

2. Son colocados en el soporte durante el proceso de impresión.

3. ${ }^{\circ}$ Y están adheridos al soporte durante el proceso de inclusión de datos.

En la actualidad, existe infinidad de modalidades falsarias dependiendo de la naturaleza del soporte y de la mayor implicación o no, en la incorporación de medidas de seguridad al mismo por el órgano emisor, lo cual, hará que su manipulación sea más compleja al falsario, dependiendo del grado de protección que blinda al documento, de ahí que el falsario sienta predilección por unos soportes más que por otros $^{68}$.

${ }^{67}$ A modo de ejemplo, los permisos de conducción de la Unión Europea se rigen por la Directiva 2006/126/CE para expedir e incorporar al tráfico jurídico el modelo comunitario que figura en el anexo I de la Directiva. En la misma viene recogido las medidas de seguridad mínimas que debe de llevar un permiso de conducción, dejando a los Estados miembros cierta discrecionalidad para incorporar más medidas si éstos los ven oportuno.

${ }^{68}$ En este sentido los autores GuILlÉn Pérez, V., «Aplicación jurídica del permiso de conducir provisional y de la UE: introducción a la documentoscopia», Aspectos criminológicos en materia de seguridad vial, Ed. Criminología y Justicia, España, 2015, pág. 211, y Nieto Alonso, J., "Apuntes de...» op. cit., 1998, pág. 169, arguyen que los fondos de seguridad de muchos documentos, están formados por un complejo de entrelineados y dibujos, la impresión formada en iris consistirá en la estampación de tintas convertibles que reaccionan cambiando de tono, caracterizada porque 
Entre algunas modalidades falsarias podemos hallar entre otras ${ }^{69}$ :

- Expediciones fraudulentas: tratándose éstas de documentos sustraídos en blanco o extraviados, los cuales son cumplimentados por personas no autorizadas.

- Expediciones legales mediante fraude: Son documentos expedidos por la autoridad o funcionarios competentes, pero obtenidos mediante engaño o corrupción.

- Uso indebido de documentos sin manipular: Utilización de documentos auténticos sin manipular de otra persona (documentos de identidad, tarjetas de personas de movilidad reducida, etc.), subsumibles en el artículo 400 bis del Código Penal, introducido por la Ley Orgánica 5/2010, de 22 de junio. En este sentido, del tenor literal del precepto citado equipara el uso de documento auténtico por quien no está legitimado, como una falsedad documental ${ }^{70}$. A modo de ejemplo, citamos la sentencia del Tribunal Supremo ${ }^{71}$, cuyo fallo estima oportuno aplicar el artículo 400 bis del Código Penal, a un individuo de nacionalidad de Ghana, que se hizo pasar por otra persona en el aeropuerto de Gran Canaria, para eludir un delito que días antes había cometido.

En base a lo expuesto una vez detectadas ciertas anomalías en el soporte se realizaría una inspección más exhaustiva, cotejando el documento objeto de estudio con aquellos documentos especímenes o Indubitados (genuinos), con el fin de hallar aquellos posibles errores que haya podido cometer el falsificador.

Si bien en la actualidad queda demostrado que todo agente policial debe tener conocimientos básicos en la detección de documentación falsa o falsificada, en aras del mantenimiento del libre ejercicio de los derechos y libertades de los ciudadanos, blindando con ello la seguridad de sus documentos y su posible utilización ilegítima, vulnerando con ello sus derechos fundamentales reconocidos en nuestra Carta Magna, ya que sin una constante implicación y especialización policial sería infructuoso.

son tintas delebles, lo que proporciona a las FCS observar con más viabilidad una manipulación, bien de raspado o bien de borrado.

${ }^{69}$ OMbelli, D. y KNOPJES F., «Documentos: manual», op. cit., 2011, págs. 54-55.

${ }^{70}$ A no ser que el Tribunal, acepte en los hechos fácticos una exhibición burda de un documento de quien no sea el portador legítimo para ello (SAP de Madrid, $427 / 2017$, de 30 de marzo).

${ }^{71}$ STS 199/2016, de 3 de febrero. 


\section{CONCLUSIÓN}

Las diligencias de identificación que realizan las FCS en la vía pública, tienen como objetivo verificar la verdadera identidad de las personas mediante su documentación acreditativa. A este respecto, la nueva LOPSC, regula una serie de preceptos que posibilitan la identificación de los ciudadanos a requerimiento de las FCS, protegiendo y garantizando sus derechos fundamentales mientras son sometidos a dicha práctica; así como que habilita a los propios agentes policiales a verificar las medidas de seguridad de los documentos de identidad.

En relación a ello, la nueva LOPSC, se convierte en un nexo indispensable que satisfará la tarea administrativa de la identificación junto con la documentoscopia, a fin de lograr la auténtica identidad de un sujeto que va a ser sometido a la diligencia de la identificación. Para ello, será requisito indispensable el conocimiento de las nociones jurídicas básicas para que, tanto su identificación como su traslado y exhibición de su documento, guarden siempre el justo equilibrio con respecto a la protección de sus derechos fundamentales.

En cualquier caso, entendemos que existen dos campos interrelacionados:

En primer lugar, aseveramos que el vínculo de esta tarea identificativa lo conforman los artículos 9 y 13 de la LOPSC. Del tenor literal de estos preceptos, y a diferencia de lo dispuesto por la antigua y derogada LOPSC de 1992, se deriva claramente, no dejando opción alguna a otra interpretación, que tanto españoles como extranjeros, que sean requeridos por un agente de la autoridad, estarán obligados a exhibir su documento con el fin de que puedan comprobarse sus correspondientes medidas de seguridad, sin perjuicio de las consecuencias coercitivas pertinentes que se derivasen en caso de desobediencia. Esto es, en el supuesto de que el sometido a identificación se negare a entregar al funcionario policial actuante su documentación identificativa, y que previamente hubiese sido requerida para su estudio o análisis, aquél podrá incurrir en una infracción penal o administrativa, atendiendo a las circunstancias concurrentes del caso.

En este sentido, el lector debe saber, y tener la absoluta certeza, que este tipo de actuaciones no obedece a un mero capricho, o a una arrogante demostración de superioridad realizada por parte de los agentes del orden, sino a una vocación sincera y abnegada puesta al servicio de la ciudadanía, a la que deben proteger en tiempos en los que tanto los grupos terroristas, como las organizaciones criminales de toda índole, campan a sus anchas, cruzan fronteras, transitan y 
circulan libremente, portando consigo toda clase de documentaciones falsificadas, manipuladas o alteradas a fin de pasar desapercibidos. Así pues, se ha de comprender que los integrantes de las FCS, en el ejercicio de sus funciones de prevención, deban examinar, con cierto celo y garantía, los documentos oficiales o públicos, especialmente aquellos que hayan sido expedidos con sus correspondientes medidas de seguridad, a fin de detectar, ya no solo la comisión de delitos de falsedad documental o infracciones administrativas, sino también a aquellos criminales y terroristas que amenazan y ponen en peligro nuestras normas de convivencia inspiradas en la Declaración Universal de los Derechos Humanos.

Ahora bien, y continuando con los párrafos anteriores, la documentoscopia es concebida como la última herramienta, al alcance del policía, con la que verificar la autenticidad de un documento. Por consiguiente, destacamos que, por ello, es necesario proporcionar a los miembros de las FCS aquellos conocimientos específicos y concernientes a esta área, tanto en la detección en sus distintas modalidades falsarias, como en la normativa que regula el propio documento que esté siendo examinado. Por eso, consideramos de suma importancia el primer nivel, consistente en el examen del propio soporte; es decir, la inspección visual y táctil realizada por las FCS sobre el propio documento inspeccionado, sin mediar ningún tipo de aparato, y que permita identificar, en su caso, un documento falsificado.

Y en segundo lugar, nos referimos al artículo 16 de la LOPSC, cuyo contenido regula la identificación y sus traslados a dependencias policiales. En cuanto a la identificación se refiere, puede resultar confuso, para los intervinientes, un requisito indispensable para la correcta práctica de las identificaciones aludida por susodicho artículo: el indicio. Ahora bien, entendemos que la doctrina jurisprudencial ha ido marcando y modulando tanto el término «sospecha» como el propio «indicio", hasta referirse, con ellos, a lo mismo, a pesar de que ambas locuciones contienen, respectivamente, significados diferentes. Sin ir más lejos, alguna sentencia viene a asentar, como criterio que justifique tal identificación, la propia experiencia de las FCS, puesto que les permitirá valorar datos que pasarían desapercibidos a personas no expertas. Además, respecto a la identificación con fines de prevenir una infracción administrativa, y que fue extinguida con la aprobación de esta nueva Ley, aportamos una solución operativa que justificará esta clase de actuación policial. En este sentido, entendemos que una identificación estará justificada siempre y cuando el motivo sea prevenir, en primera instancia, una infracción penal, aunque al mismo tiempo se hubiese tenido el objetivo, igualmente, de 
prevenir una infracción administrativa. Por último, y en cuanto a los traslados a efectos de identificación se refiere, atendiendo al principio de proporcionalidad, concluimos que estarán legitimadas todos aquellas actuaciones de esta naturaleza que tengan la finalidad de sancionar una infracción administrativa catalogada como de «seguridad ciudadana».

\section{BIBLIOGRAFÍA}

Agudo Fernández, E., Jaén Vallejo, M., y Perrino Pérez, A. L., Terrorismo en el siglo XXI, Ed. Dykinson, Madrid, 2016.

Albel Lluch, X., Derecho probatorio, Ed. Bosch Editor, Barcelona, 2012.

Alonso Pérez, F. (Coord.), Manual del policía, Ed. La Ley Actualidad, Madrid, 2004.

Banacloche Palao, J., La libertad personal y sus limitaciones, Ed. MacGraw-Hill, Madrid, 1996.

BiLbao UbiLlos, J. M., «La llamada ley mordaza: Ley Orgánica 4/2015 de Protección de la Seguridad Ciudadana», Teoría y Realidad Constitucional, núm. 36, Uned, 2015, págs. 217-260.

Caballero Chaparro, J., «Documentoscopia», Repositorio Institucional de la Universidad de Málaga, 2015.

Casal Hernandez, J. M., Derecho a la libertad personal y diligencias policiales de identificación, Ed. Centro de estudios políticos y constitucionales, Madrid, 1998.

Colina Arenas, J. D., «Apuntes acerca de la documentoscopia como disciplina auxiliar de la criminalística», Revista Facultad de Ciencias Forenses y de la Salud, núm. 8, Noviembre 2012, págs. 19-26.

De Antón y Barberá y De Luis y Turégano, Policía científica, Vol. 2 , 4. ${ }^{\circ}$ Edición, Ed. Tirant lo Blanch, Valencia, 2004.

Del Pichia, J., Tratado de Documentoscopia. La falsedad documental, Ed. La Rocca, Buenos Aires, 1993.

DÍAZ ARIAS, A., «Documentación e identificación personal. Identificación de personas (Capítulo III), Jornadas de formación de formadores sobre la nueva Ley Orgánica 4/2015, de Protección de la Seguridad Ciudadana, Madrid, 2015. 
Díaz Santana, O. F., "La prueba pericial de datación de documentos», Diario La Ley, núm. 8937, Sección Tribuna, 2017.

DuART AlBIol, J. J., Inspecciones; registros e intervenciones corporales en el proceso penal, Ed. J. M. Bosch, Barcelona, 2014.

España Alcoba, F., «La nueva Ley de Seguridad Ciudadana y los derechos y libertades de la ciudadanía española», en RIVERA BEIRAS, I., (Dir.), Tesis doctoral, Universitat de Barcelona, 2015.

Fernández Martínez, J. M., (Coord.), Diccionario jurídico, Ed. Aranzadi, 2004.

García Alonso, D., «Intervención policial en seguridad y protección ciudadana», Área de derecho penal, Universidad Pública de Extremadura, 2016.

GERCKE, M., «Enfoques jurídicos para tipificar el delito de hurto de identidad", Manual sobre los delitos relacionados con la identidad, Ed. Oficina de las Naciones Unidas contra la Droga y el Delito, Nueva York, 2013.

GRILlo M. A., «La falsificación de documentos, la importancia del perito documentológico privado», Revista Jurídica: Gaceta Judicial, República Dominicana, 1998.

GuILLÉN ÁlVAREZ, I., «Estudio y análisis jurídico de la nueva Ley Orgánica 4/2015, de protección de la seguridad ciudadana», Diario la Ley, núm. 8633, 2015.

GuILlén Pérez, V., La práctica del cacheo en el sistema constitucional español, Ed. Iuris Universal, Murcia, 2016.

- «Aplicación jurídica del permiso de conducir provisional y de la UE: introducción a la documentoscopia», Aspectos criminológicos en materia de seguridad vial, Ed. Criminología y Justicia, España, 2015.

Magaz Álvarez, R., «Respuestas políticos-criminales a la delincuencia internacional: narcotráfico y terrorismo», en Collado Medina, J., La investigación criminal y sus consecuencias jurídicas, Ed. Dykinson, 2010, Madrid.

Martínez Atienza, G., Seguridad pública y privada, Ed. Vlex, Barcelona, 2016.

Mendoza Bremauntz, E., "La investigación científica del delito», Revista Criminogénesis, núm. 1, México, 2007, págs. 435-465. 
Miguel Salas, I., «El análisis de los documentos y la perspectiva criminológica», En Ezeiba Ramos, J. (Dir.), Universidad del País Vasco. Euskal Herriko Unibertzitatea, 2015.

Nieto Alonso, J., Apuntes de Criminalística, Ed. Tecnos, Madrid, 1998.

OMBELLI, D. y KNopJEs F., «Documentos: manual para desarrolladores», Ed. Organización Internacional para Migraciones, Ginebra, 2011.

Otamendi ZozaYa, F., La nueva Ley Orgánica 4/2015, de Protección de la Seguridad Ciudadana: Una visión práctica, Ed. AMAL, Pamplona, 2015.

Otero Soriano, J. M., Criminalística y policía científica, La investigación criminal y sus consecuencias jurídicas, Ed. Dykinson, Madrid, 2010.

Otero Soriano, J. M., Criminalística y policía científica, en Collado Medina, J. (Coor.), Teoría y práctica de la investigación criminal, Ed. Instituto Universitario General Gutiérrez Melado, Uned, Madrid, 2009, pág. 103.

Polizia Zientifikoaren Unitatea (Unidad de Policía Científica), «Operaciones fundamentales de criminalística», Gobierno Vasco, Departamento de Interior, País Vasco, 2000.

Prieto González, J., Manuales operativos de intervención policial, Volumen 1, 2. ${ }^{a}$ edición, Ed. Netpol Seguridad S. L., Madrid, 2017.

Puigserver Martínez, J. A., «La Ley Orgánica 4/2015, de 30 de marzo, de protección de la seguridad ciudadana», en MARTín DE LA VEGA, M. R. (Dir.), Seguridad y ciudadanía; Revista del Ministerio del Interior, núm. 14, Ed. Revista del Ministerio del Interior, 2015, págs. 49-68.

QueREDA TAPIA, A., "Análisis del régimen sancionador establecido en la Ley Orgánica 4/2015, de 30 de marzo, de Protección de la Seguridad Ciudadana», Revista del Gabinete Jurídico de Castilla la Mancha, 2015, págs. 94-132.

RaÑE Aguilá, L., "La Criminalística y sus diferentes disciplinas forenses para la investigación criminal», Diario La Ley, núm. 8332, Sección práctica forense, 2014.

RoJas AguiRre, L. E., "Falsedad documental como delito de engaño», Revista chilena de derechos, Vol. 41, Núm. 2, 2014, págs. 523-554.

Tobajas Santamaría, G., Domínguez Peralta, R. M., y González YubeRO, A., «Diploma de actualización profesional/Perito judicial en

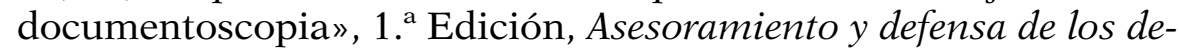
rechos del policía, Ed. Uned, 2013. 